\title{
The role of patient and physician advocacy in reducing wait times for cancer care: a qualitative analysis
}

\author{
Maria Mathews PhD, Donna Bulman PhD, Dana Ryan MA
}

Abstract

Background: There is growing interest in the role of physician as health advocate; however, few studies have documented advocacy from the patient's perspective. To address this gap, we examined the experiences of patients with cancer from the onset of symptoms to the start of treatment in Newfoundland and Labrador and aimed to describe wait times and efforts to improve timeliness of care from the patients' perspective.

Methods: We conducted qualitative interviews with 60 participants aged 19 years or more with breast, colorectal, lung or prostate cancer who were recruited from a survey of patients with cancer that was carried out as an earlier part of a larger study. All survey participants had received care at regional cancer clinics in Newfoundland and Labrador and were selected by means of purposive sampling based on their type of cancer, level of satisfaction with care and place of residence (urban, semiurban or rural). Interviews were transcribed verbatim and coded by means of a thematic approach.

Results: Participants described actions taken by themselves, their families/friends or members of their health care team to reduce their wait for a diagnosis and/or treatment. In all instances, participants believed that these actions resulted in more timely care. Participants reported that "insider knowledge" of health care professionals (whether friends, family members or members of the care team) was particularly valuable in reducing delays.

Interpretation: The use of advocacy was relatively commonplace. The role of advocacy, whether it originates from patient or caregiver, is important to ensure access to timely, good-quality cancer care.

elf-advocacy plays an important role for patients in the health care system. ${ }^{1-3}$ Self-advocacy includes requesting up-to-date information about particular health conditions, obtaining multiple medical opinions and fighting for specific rights related to privacy and employment. ${ }^{4}$ Despite the recognition that self-advocacy is commonplace, there are few empirical studies that document how patients or their families, friends or health care providers attempt to influence access to care, particularly in relation to wait times. ${ }^{5}$ To date, much of the literature has been negatively framed (i.e., "queue-jumping" [receiving personally convenient care at the expense of others]). ${ }^{6-8}$ Physicians are increasingly expected to advocate for patients; ${ }^{9-13}$ in fact, physician as health advocate is a core competency of medical training in Canada. ${ }^{14}$ Although a small number of studies have examined the advocacy roles of physicians from a physician perspective, ${ }^{12-14}$ few investigators have examined patients' perspectives, particularly in relation to reducing wait times.

We used qualitative interviews with patients with cancer to examine their experiences from the onset of symptoms to the start of treatment in Newfoundland and Labrador. This study was part of a larger study examining patients' wait times and wait-related satisfaction with cancer care.${ }^{15}$ In the larger study, we found that wait-related satisfaction was not necessarily related to actual wait time (patients with short waits may be unsatisfied, whereas patients with long waits may be satisfied) and that the wait time to diagnosis was particularly important to patients and predicted satisfaction with subsequent waits. ${ }^{15,16}$ Through qualitative interviews, we found that whether the delay was avoidable or was attributable to the patient, provider or health care system did not explain patient wait-related satisfaction. ${ }^{17}$ Instead, we found that patients' self-described satisfaction was related to 3 overlapping and interconnected dimensions: patient-perceived timeliness of care, physicians' interpersonal skills and coordination of care. ${ }^{18}$ In the current study, we describe patients' perspectives of their efforts to improve the timeliness of their care. Given that wait times are an important issue in the Canadian context, ${ }^{19,20}$ studying waits of patients with cancer provides a robust opportunity to understand how patients attempt to expedite their care.

Competing interests: None declared.

This article has been peer reviewed.

Correspondence to: Maria Mathews, mmathews@mun.ca

CMAJ Open 2017. DOI:10.9778/cmajo.20170039 


\section{Methods}

\section{Setting and design}

The study was conducted between November 2009 and July 2011. All participants were recruited from a survey of patients with cancer that was carried out as part of our larger study. ${ }^{15}$ All survey participants had received care at regional cancer clinics in Newfoundland and Labrador. We carried out qualitative interviews in addition to the survey to allow us, as health care services researchers, to explore in greater detail differences in patients' expectations of care and the organization of services in relation to wait-related satisfaction, disease or place of residence (urban v. rural). Using purposive sampling, ${ }^{21,22}$ we invited patients to participate in an interview on the basis of their type of cancer (breast, colorectal, lung or prostate), level of satisfaction with their wait for cancer care (satisfied or unsatisfied with any wait time) and residence (urban [population $\geq 100000$ ] semiurban [population 10000 99 999] or rural [population < 10000 ]). These data were gathered through the initial survey. For each type of residence and cancer we interviewed at least 3 patients. We also ensured that both satisfied and unsatisfied patients were included within the sample. Interviews continued until data saturation was reached (i.e., until no new themes emerged among the participants' responses)..$^{21,22}$

\section{Participants}

Eligible participants were 19 years of age or older, were Newfoundland and Labrador residents and had received a diagnosis of breast, colorectal, lung or prostate cancer. Participants with previous or multiple cancer diagnoses were excluded.

\section{Data source}

Interviews were conducted in English, in person or by telephone, by trained research assistants. All interviews were recorded and transcribed verbatim. During the interviews, participants were asked semistructured questions related to the cause of wait times from the onset of their symptoms to accessing treatment, how they believed wait times could be reduced, what barriers (personal, disease-related or systemrelated) they had experienced when trying to access care and how satisfied they were with their wait times (Appendix 1, available at www.cmajopen.ca/content/5/4/E773/suppl/DC1). These broad questions allowed participants the opportunity to talk about any activities they believed may have influenced wait times. In each interview, we conducted member checking to ensure that we understood participants' responses. ${ }^{21}$

\section{Analysis}

We conducted a thematic analysis. ${ }^{21,23}$ All of the researchers individually read a random sample of the transcripts to identify key terms and themes. Once agreement was reached among all members of the team on the key themes and definitions, we developed a coding template ${ }^{21,23}$ that was used to code all interviews ${ }^{22}$ with the use of NVivo software. Two researchers (M.M. and D.R.) read all the interview transcripts.
We kept an audit trail to document all transcripts and coding templates. Disagreements in coding were resolved by consensus. To protect confidentiality, participants are described by number, and quotations were edited to remove identifying features.

\section{Ethics approval}

The Memorial University Human Investigation Committee approved this study.

\section{Results}

We identified 128 survey respondents who met the inclusion criteria. We invited 90 respondents to participate in an interview, of whom 60 (aged 38-84 yr) completed an interview and 30 declined because they were not interested, could not schedule a time or were in too poor health to participate. Of the 60 interviews, 58 were conducted by telephone. The interviews lasted 8-82 (mean 27) minutes. The participants' demographic characteristics and overall satisfaction with wait times are presented in Table 1; $36(60 \%)$ were satisfied, and $24(40 \%)$ were unsatisfied. Slightly over half (33 [55\%]) of the participants described actions taken by themselves, their families/friends or members of their health care team to reduce their wait for a diagnosis and/or treatment. There were no differences in the actions taken to reduce wait times between patients who were satisfied and unsatisfied with wait times or between the 4 cancer types.

\section{Efforts by patient to reduce wait times}

To expedite their care, patients insisted on 1) having tests for symptoms, 2) following up on test results and 3) arranging appointments themselves. Participants believed that their actions ensured that they received information or care faster than if they had been more passive and simply waited for information about test results or appointments to be provided to them. Participants perceived that delays they had experienced stemmed from miscommunication between members of the health care team or a lack of understanding of the patient's unique circumstances. For example, a participant who had seen a physician for a persistent cough and had been prescribed antibiotics and been sent home on 2 prior visits insisted that his doctor order chest radiography (Table 2, quotation 1). Not all efforts to insist on tests were met with success. For example, a participant who had reported stomach pain encountered resistance when she suggested endoscopy (Table 2, quotation 2). She initially had tests for celiac disease but described having to hunt down her test results herself (Table 2, quotation 3). The woman believed that her doctor would not consider other investigations or conditions until celiac disease had been ruled out. Given her subsequent diagnosis of cancer, the participant felt that the physician was uncaring, and she believed that his unwillingness to help her increased the time it took to get a diagnosis. Another participant noted that advocating for oneself, especially for tests that a physician believed were not needed, could sour the doctorpatient relationship (Table 2, quotation 4). 


\begin{tabular}{|c|c|c|c|c|c|}
\hline \multirow[b]{2}{*}{ Characteristic } & \multicolumn{5}{|c|}{ Cancer type; no. (\%) of participants } \\
\hline & $\begin{array}{l}\text { Breast } \\
n=18\end{array}$ & $\begin{array}{c}\text { Colorectal } \\
n=15\end{array}$ & $\begin{array}{l}\text { Lung } \\
n=11\end{array}$ & $\begin{array}{c}\text { Prostate } \\
n=16\end{array}$ & $\begin{array}{c}\text { All types } \\
n=60\end{array}$ \\
\hline \multicolumn{6}{|l|}{ Sex } \\
\hline Male & $0(0)$ & $11(73)$ & $6(54)$ & $16(100)$ & $33(55)$ \\
\hline Female & $18(100)$ & $4(27)$ & $5(45)$ & $0(0)$ & $27(45)$ \\
\hline \multicolumn{6}{|l|}{ Age } \\
\hline$<65$ & $16(89)$ & $10(67)$ & $6(54)$ & $8(50)$ & $40(67)$ \\
\hline$\geq 65$ & $2(11)$ & $5(33)$ & $5(45)$ & $8(50)$ & $20(33)$ \\
\hline \multicolumn{6}{|l|}{ Cancer stage } \\
\hline Early & $11(61)$ & $0(0)$ & $2(18)$ & $4(25)$ & $17(28)$ \\
\hline Late & $6(33)$ & $9(60)$ & $7(64)$ & $12(75)$ & $34(57)$ \\
\hline Unknown & $1(6)$ & $6(40)$ & $2(18)$ & $0(0)$ & $9(15)$ \\
\hline \multicolumn{6}{|l|}{ Residence } \\
\hline Urban & $6(33)$ & $5(33)$ & $1(9)$ & $3(19)$ & $15(25)$ \\
\hline Semiurban & $6(33)$ & $4(27)$ & $2(18)$ & $4(25)$ & $16(27)$ \\
\hline Rural & $6(33)$ & $6(40)$ & $8(73)$ & $9(56)$ & $29(48)$ \\
\hline \multicolumn{6}{|l|}{ Marital status } \\
\hline Married or equivalent & $16(89)$ & $13(87)$ & $10(91)$ & $16(100)$ & $55(92)$ \\
\hline Single & $2(11)$ & $2(13)$ & $1(9)$ & $0(0)$ & $5(8)$ \\
\hline \multicolumn{6}{|l|}{$\begin{array}{l}\text { Overall satisfaction with } \\
\text { wait times }\end{array}$} \\
\hline Dissatisfied & $9(50)$ & $6(40)$ & $3(27)$ & $6(38)$ & $24(40)$ \\
\hline Satisfied & $9(50)$ & $9(60)$ & $8(73)$ & $10(62)$ & $36(60)$ \\
\hline
\end{tabular}

Participants believed that, by taking the initiative, they received care faster. One participant reported that, while waiting for a surgery date, she contacted the surgeon's office, and there was no record of her referral (Table 2, quotation 5). She was quickly scheduled for surgery following a telephone call by her referring gastroenterologist. Another participant, who had advocated for an earlier appointment, felt that her wait would have been longer if she had passively waited for the system to work (Table 2, quotation 6). She reported that the hospital appointments service called her back to set an appointment time within 10 minutes of her telephoning them.

For rural patients, playing an active role in determining when and where appointments took place could result in earlier appointments. Rural patients can see cancer specialists in St. John's or during "travelling clinics" to the smaller, regional centres. Rural participants were able to get more timely appointments by contacting the staff and indicating a willingness to travel or attend a particular clinic (Table 2, quotation 7).

A participant who worked in the health care system believed that her work experience gave her an advantage in arranging her care. As a nurse, she was familiar with the testing procedures and the general timelines that her care should have followed. She noted that she knew who to ask and when information should be provided (Table 2, quotation 8). She believed that this "insider knowledge" helped her in advocating for herself and reduced time waiting for care.

\section{Efforts by family and friends to reduce wait time times}

Family members and/or friends may assume the responsibility of advocating for the patient or coordinating care. A participant with prostate cancer reported that his wife called to see whether there was an earlier appointment available for him if he travelled to St. John's rather than wait for a travelling clinic (Table 2, quotation 9). In another example, the wife of a participant with colorectal cancer was displeased about the amount of time it was taking for her husband's treatment to start. She called the cancer clinic to advocate on his behalf, which resulted in a video conference with an oncologist, who then helped arrange the participant's care (Table 2, quotation 10).

Participants also relied on family members or friends with connections in the health care system. The daughter of a participant with breast cancer used her connection to arrange an appointment with a specific doctor who was otherwise unavailable to see the participant (Table 2, quotation 11). Another participant, who was unable to convince her doctor to provide her with a copy of her pathology report, called a friend who was a resident radiologist for help. The friend 
Table 2: Themes and illustrative quotations

\begin{tabular}{|c|c|c|}
\hline Theme & $\begin{array}{l}\text { Quotation } \\
\text { no. }\end{array}$ & Illustrative quotation \\
\hline \multirow[t]{8}{*}{$\begin{array}{l}\text { Efforts by patient to } \\
\text { reduce wait times }\end{array}$} & 1 & $\begin{array}{l}\text { And the third time I went back, I asked him if he would send me for a chest x-ray ... because I was } \\
\text { getting concerned that there might be something else. And he did, he sent me for a chest x-ray, and the } \\
\text { reports came back that there was a ... mass on my lung. (ID 337, man, lung cancer, rural, satisfied) }\end{array}$ \\
\hline & 2 & $\begin{array}{l}\text { I kept saying "my tummy doesn't feel right, I feel like there's something wrong. Maybe you could do } \\
\text { an endoscopy test," and [the physician is], like, "You're } 39 \text { and you don't have any symptoms, there's } \\
\text { nothing wrong with you." And they basically laughed in my face that I was complaining so much. } \\
\text { (ID 219, woman, colorectal cancer, semiurban, dissatisfied) }\end{array}$ \\
\hline & 3 & $\begin{array}{l}\text { So I spent a few months being tested for celiac; that test got lost in the system. Four months later, I } \\
\text { tracked it down myself, and my family doctor refused to look for it ... because he just assumed } \\
\text { when it's ready it would show up on his computer.... Eventually I phoned the blood laboratories in } \\
\text { St. John's and found my results and it came back negative. (ID } 219, \text { woman, colorectal cancer, } \\
\text { semiurban, dissatisfied) }\end{array}$ \\
\hline & 4 & $\begin{array}{l}\text { And the problem with pressing is that the doctors, a lot of them will say, "The hell with you, get the } \\
\text { hell out," you know? So you're caught between a rock and a hard spot. (ID 224, man, colorectal } \\
\text { cancer, urban, dissatisfied) }\end{array}$ \\
\hline & 5 & $\begin{array}{l}\text { I called [the referring gastroenterologist] back and said, "Look, [the surgeon] says I'm not on her list, } \\
\text { or there's no list, I'm not on her surgery list," and he said, "Well, I definitely gave [your file] to her." } \\
\text { So he said, "I'll call her right away myself." (ID 231, woman, colorectal cancer, urban, satisfied) }\end{array}$ \\
\hline & 6 & $\begin{array}{l}\text { I think if I had sat home and just waited for the phone to ring, it would have been delayed a lot } \\
\text { longer. But I called up to the appointments and insisted that an appointment be given ASAP. } \\
\text { (ID 231, woman, colorectal cancer, urban, satisfied) }\end{array}$ \\
\hline & 7 & $\begin{array}{l}\text { In my case, I didn't even ask [about travelling clinics], because I just said "Whenever I can." } \\
\text { Because if they came to Clarenville, you would have to wait for whenever they came to Clarenville. } \\
\ldots \text { And for me I wanted to see them at the earliest appointment, so I was willing to travel. (ID 117, } \\
\text { woman, breast cancer, rural, satisfied) }\end{array}$ \\
\hline & 8 & $\begin{array}{l}\text { I mean, I work in the health care system, and I think that gave me a little bit of an up on who to call. } \\
\text {... Anyone in the general public, who is waiting on this stuff ... doesn't know how to insist, how to } \\
\text { really self-advocate; unless you really know the system and know how to navigate it, you're kind of } \\
\text { a victim of it and you're waiting and waiting. (ID 107, woman, breast cancer, urban, dissatisfied) }\end{array}$ \\
\hline \multirow[t]{4}{*}{$\begin{array}{l}\text { Efforts by family and } \\
\text { friends to reduce } \\
\text { wait times }\end{array}$} & 9 & $\begin{array}{l}\text { So I was waiting and waiting and waiting [to hear about the travelling clinic to Corner Brook] ... and } \\
\text { then the wife said, "I think it's time for us to try to do something," and so she phoned St. John's ... } \\
\text { and the [clerk] said, "Well, if you can be here" for such a time or whatever it was, I think it was only } \\
\text { a couple of days or something, "you can get in to see him." I said, "Great ... I'll drive to St. John's." } \\
\text { [If] I [had] had to wait for him to come into Corner Brook ... I think it [would have been] another } \\
\text { month longer. (ID } 445, \text { man, prostate cancer, semiurban, dissatisfied) }\end{array}$ \\
\hline & 10 & $\begin{array}{l}\text { And we met with [the oncologist] through video conference and he ran upstairs and he got one of } \\
\text { his colleagues to see when they could do radiation, and he came back and he had the appointment } \\
\text { dates and everything to go into St. John's. (ID 223, man, colorectal cancer, rural, dissatisfied) }\end{array}$ \\
\hline & 11 & $\begin{array}{l}\text { My daughter, who's a nurse in Nova Scotia, she had contacts with a doctor there, and he had } \\
\text { contacts with Newfoundland. ... Someone in St. John's knew this [doctor's name] in Clarenville. And } \\
\text { she [the doctor] was full but she agreed to take me [as a patient]. (ID 103, woman, breast cancer, } \\
\text { rural, dissatisfied) }\end{array}$ \\
\hline & 12 & $\begin{array}{l}\text { So I ended up on the phone with my friend who is a resident radiologist, she told me to go on down } \\
\text { to the cancer centre. So I called the cancer centre first and a friend of mine ... she answered the } \\
\text { phone. I didn't even know she worked at the cancer centre.... And we started talking and she said, } \\
\text { "Come on down and [oncologist's name] will see you." So my husband and I walked down that } \\
\text { afternoon and walked into [the oncologist's] office, like without an appointment or anything. (ID 104, } \\
\text { woman, breast cancer, semiurban, dissatisfied) }\end{array}$ \\
\hline \multirow{3}{*}{$\begin{array}{l}\text { Efforts by members } \\
\text { of health care team } \\
\text { to reduce wait times }\end{array}$} & 13 & $\begin{array}{l}\text { "And in our opinion," the doctor wrote, "[patient's name] should not have to wait that long. And it } \\
\text { would be advisable to seek other options for him." (ID 449, man, prostate cancer, rural, dissatisfied) }\end{array}$ \\
\hline & 14 & $\begin{array}{l}\text { So I asked [the surgeon] ... "Do you ... confer with an oncologist, or is it not done that way?" He said, } \\
\text { "No, it's not normally done that way," but he said, "If you want to speak to one, I'll set up an } \\
\text { appointment." Which he did ... the very next Wednesday, I had an appointment with [the oncologist] at } \\
\text { the cancer clinic.... And I didn't know how long that was going to take, but [the surgeon] ... contacted } \\
\text { that unit and ... explained to them that [I] needed to have this done ... pretty much ASAP. And I was } \\
\text { scheduled in as quick as they could get me in. (ID 118, woman, breast cancer, urban, satisfied) }\end{array}$ \\
\hline & 15 & $\begin{array}{l}\text { When [the family doctor] made an appointment for the [computed tomography] scan, he said, "I'm going } \\
\text { to set you up for a colonoscopy just in case, down the road; I'll make an appointment now, so ... you } \\
\text { won't have so much lead time if you do need one." (ID 226, man, colorectal cancer, semiurban, satisfied) }\end{array}$ \\
\hline
\end{tabular}


suggested that she go to the cancer centre, where, it turned out, another friend worked, and the participant was able to talk to an oncologist about her report that same afternoon (Table 2, quotation 12).

\section{Efforts by members of health care team to reduce wait times}

Members of a participants' health care teams, including family physicians, specialists and nurses, also worked on behalf of participants to help them access information or health care services in a timely manner. A participant who was told he had an initial wait of 9 months for surgery described how 1 of his referring surgeons wrote a letter on his behalf, advocating that he be prioritized for surgery in Halifax (Table 2, quotation 13). Similarly, a surgeon advocated on behalf of a participant with breast cancer so that she could get more information before agreeing to undergo mastectomy (Table 2, quotation 14). In another example, a family physician helped reduce the wait of a participant with colorectal cancer by proactively requesting a follow-up test (Table 2, quotation 15).

\section{Interpretation}

In this qualitative study among patients with cancer, over half of participants described attempts to reduce waits and improve access to care. Participants believed that these actions reduced their wait times and provided access to care (e.g., tests, professionals) that they would not otherwise have received. The data suggest that participants believed these actions were justified to ensure that needed tests were done, that results were communicated in a timely and correct manner, or that referrals to more appropriate or preferred practitioners were made. Although timely care was an underlying concern, the participants' motivation appeared to be obtaining appropriate and high-quality care rather than jumping the queue. For these patients, passively waiting for the system meant waiting for poor-quality care and increasing their personal stress and anxiety.

Our findings are consistent with those of studies that have investigated self-advocacy in cancer care and patients' attempts to reduce wait times. In their study of women with ovarian cancer, Hagan and Donovan ${ }^{24}$ described self-advocacy as way for patients to act in their own best interest to deal with a cancer diagnosis and treatment, including by negotiating with care providers. With the exception of paying for faster access, our participants confirmed activities described in previous studies, including calling upon doctors and other health care professionals to expedite appointments and order further tests. ${ }^{6,7}$

Our study highlights the role of health care professionals in facilitating access to care for patients with cancer. Many patients may have had limited interaction with the health care system (particularly at the secondary and tertiary level) before their cancer diagnosis and may find the system complex and difficult to navigate. Participants who worked in the system or had a family or friend with a health care background seemed to be better able to navigate the system than participants without this support. The willingness of health care professionals to assume the advocate role underscores the importance of insider knowledge of how the system works and its potential pitfalls. $8,25,26$ The actions of physicians described by our participants are consistent with descriptions of the health advocate competency ${ }^{9,11}$ and illustrate how this role influences the quality and timeliness of patient care. Providing physicians with practical tips to help patients navigate the system is 1 way to ensure that physicians can fulfill the health advocate role. ${ }^{14}$

\section{Limitations}

The information collected during the interviews relied on participants' self-reported waits and wait-related experiences, which are subject to recall bias. Moreover, given that our study included only participants with confirmed cancer diagnoses, actions to reduce waits seem reasonable and welljustified. Further research with people who did not ultimately receive a diagnosis of cancer or were not treated for cancer is needed for a more complete portrayal of the use of advocacy in cancer care. Finally, all but 2 interviews were done by telephone; the mode of interview (in person or by telephone) may have influenced participants' responses.

\section{Conclusion}

Patients with cancer, their families and health care professionals often engage in advocacy behaviour to expedite care and facilitate access to resources that would otherwise be unavailable (or difficult to obtain) to the patient. These interventions are relatively commonplace; more than half of study participants described attempts to improve access to various aspects of their care. Moreover, participants believed that their actions ensured they received appropriate, high-quality and timely care. Patients also rely on people who work in the health care system, including physicians, to facilitate better access on their behalf. Advocacy, whether it consists of patients acting on their own behalf or health care professionals acting on the behalf of patients, plays an important role in ensuring access to timely, good-quality cancer care.

\section{References}

1. Hagan TL, Medberry E. Patient education vs. patient experience of self-advocacy: changing the discourse to support cancer survivors. 7 Cancer Educ 2016;31:375-81.

2. Riggare $S$, Unruh T. Patients organise and train doctors to provide better care. BM7 2015;351:h6318.

3. Long Roche K, Angarita AM, Cristello A, et al. "Little big things": a qualitative study of ovarian cancer survivors and their experiences with the health care system. $\mathcal{F}$ Oncol Pract 2016;12:e974-80.

4. Hoffman B, Stovall E. Survivorship perspectives and advocacy. 7 Clin Oncol 2006;24:5154-9.

5. Sharma N. Academic literature review of preferential access to health care in Canada. In: Vertes JZ, commissioner. Health Services Preferential Access Inquiry Alberta. Volume 2: research and expert opinions. Calgary: Health Quality Council of Alberta; 2013; 217-42. Available: http://hqca.ca/studies-and-reviews/preferential -access-inquiry/ (accessed 2017 Mar. 16).

6. Alter DA, Basinski AS, Naylor CD. A survey of provider experiences and perception of preferential access to cardiovascular care in Ontario, Canada. Ann Intern Med 1998;129:567-72.

7. Friedman SM, Scofield L, Tirkos S. Do as I say, not as I do: a survey of public impressions of queue-jumping and preferential access. Eur 7 Emerg Med 2007;14: 260-4.

8. Vertes JZ, commissioner. Health Services Preferential Access Inquiry - Alberta. Volume 1: inquiry report. Calgary: Health Quality Council of Alberta; 2013. Available: http://hqca.ca/studies-and-reviews/preferential-access-inquiry/ (accessed 2017 Mar. 17).

9. Hubinette MM, Ajjawi R, Dharamsi S. Family physician preceptors' conceptualizations of health advocacy: implications for medical education. Acad Med 2014;89:1502-9. 


\section{Research}

10. Hubinette MM, Regehr G, Sayra C. Lessons from rocket science: reframing the concept of the physician health advocate. Acad Med 2016;91:1344-7.

11. Dobson S, Stéphane V, Regehr G. Agency and activism: rethinking health advocacy in the medical profession. Acad Med 2012;87:1161-4.

12. Earnest MA, Wong SL, Federico SG. Perspective: physician advocacy: What is it and how do we do it? Acad Med 2010;85:63-7.

13. Dobson S, Voyer S, Hubinette $M$, et al. From the clinic to the community: the activities and abilities of effective health advocates. Acad Med 2015;90:214-20.

14. Frank JR, editor. The CanMEDS 2005 physician competency framework: better standards. Better physicians. Better care. Ottawa: Royal College of Physicians and Surgeons of Canada; 2005. Available: www.royalcollege.ca/portal/page/portal/ rc/common/documents/canmeds/resources/publications/framework_full_e.pdf (accessed 2017 Mar. 16).

15. Mathews M, Ryan D, Gadag V, et al. Use of screening tests, diagnosis wait times, and wait-related satisfaction in breast and prostate cancer. Curr Oncol 2014;21:e441-8.

16. Mathews M, Ryan D, Gadag V, et al. Patient satisfaction with wait-times for breast cancer surgery in Newfoundland and Labrador. Healthc Policy 2016;11: 42-53.

17. Mathews M, Ryan D, Bulman D. Patient-expressed perceptions of wait-time causes and wait-related satisfaction. Curr Oncol 2015;22:105-12.

18. Mathews M, Ryan D, Bulman D. What does 'satisfaction with wait times for cancer care' mean to patients? BMC Cancer 2015;15:1017.

19. Wait times for priority procedures in Canada, 2014. Ottawa: Canadian Institute for Health Information; 2014. Available: https://secure.cihi.ca/free_products/ 2014_WaitTimesAiB_EN.pdf (accessed 2017 Mar. 16).

20. Time to close the gap: report card on wait times in Canada. Wait Time Alliance; 2014. Available: www.waittimealliance.ca/wp-content/uploads/2014/06/ FINAL-EN-WTA-Report-Card.pdf (accessed 2017 Mar. 17).

21. Berg BL. Qualitative research methods for the social sciences. 2nd ed. Boston: Allyn and Bacon; 1995.
22. Flick U. An introduction to qualitative research. 5th ed. Los Angeles: Sage; 2014.

23. Guest G, MacQueen KM, Namey EE. Applied thematic analysis. Los Angeles: Sage; 2012.

24. Hagan TL, Donovan HS. Ovarian cancer survivors' experiences of self-advocacy: a focus group study. Oncol Nurs Forum 2013;40:140-7.

25. Brashers DE, Haas SM, Neidig JL. The patient self-advocacy scale: measuring patient involvement in health-care decision-making interactions. Health Commun 1999;11:97-121.

26. Vaartio-Rajalin H, Leino-Kilpi H. Nurses as patient advocates in oncology: activities based on literature. Clin 7 Oncol Nurs 2011;15:526-32.

Affiliations: Division of Community Health and Humanities (Mathews, Ryan), Faculty of Medicine, Health Sciences Centre, Memorial University, St. John's, NL; Faculty of Nursing (Bulman), University of New Brunswick, Fredericton, NB

Contributors: Maria Mathews conceived the study. All of the authors contributed to the study design, analysis and interpretation of the data, and the drafting of the manuscript, gave final approval of the version to be published and agreed to be accountable for all aspects of the work.

Funding: This study was funded by the Canadian Institutes of Health Research (PHE-91543), the Newfoundland and Labrador Industrial Research and Innovation Fund and in-kind contributions from the Eastern Regional Health Authority and the Canadian Cancer Society - Newfoundland and Labrador Division.

Supplemental information: For reviewer comments and the original submission of this manuscript, please see www.cmajopen.ca/content/5/4/ E773/suppl/DC1. 